\title{
CARACTERIZAÇÃO CULTURAL E TOLERÂNCIA A PH EXTREMOS DE RIZÓBIOS ORIUNDOS DA REGIÃO DE BAIXO ACARAÚ NO CEARÁ
}

Mayara Gama da Cunha1, Marcelo de Sousa Pinheiro², Fernando Gouveia

Cavalcante $^{3}$, Suzana Cláudia Silveira Martins ${ }^{4}$, Claudia Miranda Martins ${ }^{4}$

1Discente de Agronomia na Universidade Federal do Ceará - Campus do Pici- Fortaleza

(CE) (gama.mayara@gmail.com)

2Doutor em Fitotecnia pela Universidade Federal do Ceará - Campus do Pici-Fortaleza (CE)

${ }^{3}$ Doutorando em Ecologia e Recursos Naturais da Universidade Federal do Ceará-Campus do Pici - Fortaleza (CE)

${ }^{4}$ Docentes do Departamento de Biologia da Universidade Federal do Ceará-Campus do Pici -Fortaleza-Ceará

Recebido em: 22/09/2018 - Aprovado em: 23/11/2018 - Publicado em: 03/12/2018 DOI: 10.18677/EnciBio_2018B79

\begin{abstract}
RESUMO
A disponibilidade de nitrogênio é um fator limitante para os sistemas de produção vegetal, as bactérias que fixam nitrogênio desempenham um importante papel nesse tipo de produção, reduzindo os custos e os impactos ambientais além do aumento na produtividade. $\mathrm{O}$ objetivo desse trabalho foi isolar, caracterizar e avaliar a tolerância a pH extremos $(\mathrm{pH} 4 \mathrm{e} \mathrm{pH} \mathrm{10)} \mathrm{de} \mathrm{rizóbios} \mathrm{obtidos} \mathrm{de} \mathrm{nódulos} \mathrm{radiculares,}$ oriundos da região de Acaraú no Ceará. Das 19 estirpes testadas, uma tornou o pH do meio alcalino e em $18 \mathrm{o} \mathrm{pH}$ manteve-se neutro. Todas apresentaram velocidade de crescimento lento, consistência do muco butírica. Para o diâmetro das colônias, uma é puntiforme, quinze têm diâmetro inferior a $1 \mathrm{~mm}$ e três têm diâmetro superior a $1 \mathrm{~mm}$. Nenhuma das estirpes foram capazes tolerar $\mathrm{pH} 4$, crescendo apenas em $\mathrm{pH} 10$.
\end{abstract}

PALAVRAS-CHAVE: bactérias diazotróficas, pH ácido, pH alcalino, semiárido

\section{CULTURAL CHARACTERIZATION AND EXTREMES pH TOLERANCE OF DIAZOTROPHIC BACTERIA FROM THE REGION OF BAIXO ACARAÚ IN CEARÁ}

\begin{abstract}
Nitrogen availability is a limiting factor for plant production systems, bacteria that fix nitrogen, play an important role in this type of production, reducing costs, environmental impacts and increase productivity. The objective of this work was to isolate, characterize and evaluate the extreme $\mathrm{pH}$ tolerance $(\mathrm{pH} 4$ and $\mathrm{pH} 10)$ of rhizobia from the Acaraú region in Ceará. Out of the 19 strains, just one turn the medium $\mathrm{pH}$ to alkaline and 18 maintained the medium $\mathrm{pH}$ at neutral. All presented slow growth and mucus with butyric consistency. According with colony diameter evaluation, one is punctiform, fifteen have a diameter less than $1 \mathrm{~mm}$ and three have a diameter greater than $1 \mathrm{~mm}$. None of the strains were able to tolerate $\mathrm{pH} 4$, growing at $\mathrm{pH} 10$ only.
\end{abstract}

KEYWORDS: diazotrophic bacteria, acid pH, alcaline $\mathrm{pH}$, semi-arid 


\section{INTRODUÇÃO}

Em muitos sistemas de produção, a disponibilidade de nitrogênio é quase sempre um fator limitante, influenciando o crescimento da planta, mais do que qualquer outro nutriente (BREDEMEIER; MUNDSTOCK, 2000). Na natureza este elemento é encontrado em abundância em uma forma quimicamente muito estável $\left(\mathrm{N}_{2}\right)$ e, portanto, sua pronta assimilação pela maioria dos seres vivos é limitada, requerendo a transformação para uma forma combinada que facilite sua assimilação (MARIN et al., 1999).

Rizóbios são bactérias do solo fixadoras de nitrogênio que formam nódulos nas raízes e/ou nos caules das leguminosas (HAN et al., 2005). A fixação biológica de nitrogênio (FBN) é realizada a partir da simbiose das espécies leguminosas com bactérias fixadoras, que formam nódulos em suas raízes, capazes de absorver o nitrogênio da atmosfera convertendo em amônia para posterior conversão em aminoácidos para nutrição vegetal (PEREIRA et al., 2017). Essa fixação biológica desempenha um importante papel nos sistemas de cultivos (SOARES et al., 2016) e na sustentabilidade dos ecossistemas (CARDOSO; ANDREOTE, 2016).

As bactérias que fixam nitrogênio são exploradas na agricultura e na silvicultura para produção e aplicação de inoculantes rizobianos que reduzem os custos e os impactos ambientais da produção vegetal, além do aumento na produtividade (HUNGRIA et al., 2015; RODRIGUES et al., 2018).

$O$ estudo da diversidade dessas bactérias que nodulam leguminosas tem aplicações agrícolas significativas. Em termos de manejo cultural, visa promover a sobrevivência de populações mais eficientes e específicas, e a obtenção de genótipos mais adaptados aos tipos de solo e tolerantes aos diferentes estresses ambientais (EHRHARDT-BROCARDO et al., 2015). O conhecimento da diversidade de bactérias diazotróficas, por meio da caracterização fenotípica é o passo inicial para a seleção de estirpes eficientes para a produção de inoculantes (SOUSA et al., 2014). A caracterização morfológica de colônias bacterianas para a avaliação de diversidade serve como um complemento importante para as análises genéticas, uma vez que possibilita a construção de agrupamentos de indivíduos morfologicamente semelhantes (NAVROSKI et al., 2015).

Alguns fatores como $\mathrm{pH}$ do solo, deficiência de nutrientes, temperatura e umidade do ambiente, podem dificultar o processo de nodulação e FBN (CARDOSO; ANDREOTE, 2016). Para que ocorra uma simbiose eficiente é necessário o conhecimento não só da disponibilidade de nitrogênio para a planta, mas também há a necessidade de analisar as características fenotípicas desses microrganismos, pois estas podem auxiliar em estudos de adaptabilidade e tolerância às condições ambientais em que essas associações simbióticas estão inseridas e que afetam a produção agrícola. Características do solo, como $\mathrm{pH}$, podem comprometer a eficiência simbiótica e desenvolvimento de plantas. Valores de pH abaixo de 5,0 são relatados como deletérios para nodulação e fixação de nitrogênio (APPUNU; DHAR, 2006). Nesse sentido, esse trabalho objetivou isolar, caracterizar e avaliar a tolerância a pH extremos ( $\mathrm{pH} 4$ e 10) de estirpes de rizóbios oriundos da região de Acaraú no Estado do Ceará.

\section{Obtenção, isolamento e purificação das colônias \\ MATERIAL E METODOS}

O experimento foi realizado no Perímetro Irrigado Baixo Acaraú (PIBAU), na Fazenda Duvalle Frutas $\left(3^{\circ} 06^{\prime} 22^{\circ} \mathrm{S} 40^{\circ} 07^{\prime} 15 \mathrm{~W}\right)$, no município de Marco 
- CE. Coletou-se amostras compostas de solo pelo método de caminhamento em ziguezague, as amostras foram coletadas na profundidade de $0-20 \mathrm{~cm}$ usando uma enxada como ferramenta. Foi utilizado o feijão-caupi (Vigna unguiculata L.) cv "setentão" como planta-isca para a obtenção dos isolados. O plantio ocorreu em triplicata, usando recipientes de $300 \mathrm{~mL}$. Antes da semeadura houve a desinfestação das sementes, mergulhando-as em etanol $95 \%$ por um período de 30 segundos, posteriormente foram mergulhadas em $\mathrm{NaClO} 5 \%$ durante 5 minutos, e lavadas seis vezes em água destilada estéril. Plantou-se três sementes em cada recipiente, decorridos sete dias após o plantio, realizou-se o desbaste mantendo uma planta por recipiente. Transcorrido 40 dias retirou-se os nódulos radiculares e acondicionou-os em frascos contendo sílica.

Os nódulos colhidos foram reidratados em água destilada durante uma hora, logo depois desinfestados com etanol absoluto durante 30 segundos seguido de $\mathrm{NaClO} 5 \%$ por três minutos, posteriormente lavados cinco vezes em água destilada estéril. Seguida a desinfestação, os nódulos foram macerados com uma pinça em placas de Petri com meio YMA (VINCENT, 1970) mais o corante vermelho congo, e incubados em estufa do tipo Biochemistry Oxigen Demand (B.O.D.) a $28^{\circ} \mathrm{C}$ por sete dias. Posteriormente efetuou-se a purificação dos isolados, por meio da seleção de colônias com aspecto arredondado e que não absorveram do corante. Essas colônias foram repicadas sucessivamente até obtenção da cultura pura dos isolados.

\section{Autenticação dos isolados}

A autenticação dos isolados ocorreu através da observação da capacidade nodulífera por meio do plantio e inoculação em feijão-caupi. O substrato empregado foi constituído por areia e vermiculita $(2: 1)$ o qual foi autoclavado a $121^{\circ} \mathrm{C}$ por uma hora. A semeadura ocorreu em recipientes de $300 \mathrm{~mL}$ aplicando-se três repetições por isolados e utilizando sementes de feijão-caupi cv. setentão. Plantou-se três sementes em cada recipiente, sendo o desbaste realizado depois de sete dias, mantendo uma planta por recipiente.

Para a preparação do inóculo foi colocado $100 \mathrm{~mL}$ do meio YM em Erlenmeyer, seguida de inclusão da cultura mantendo-a sob agitação orbital a 150 rpm no intervalo de três a seis dias até o crescimento da cultura, constatado pelo turvamento do meio. Decorrido três dias do plantio adicionou-se $3 \mathrm{~mL}$ do inóculo por recipiente contendo uma planta de feijão-caupi e aos 35 dias foram examinadas as raízes para observar a existência de nódulos, bem como, a cor avermelhada dentro dos mesmos, indicando a atividade da leghemoglobina. As estirpes autenticadas foram inseridas a coleção de culturas de bactérias diazotróficas do Laboratório de Microbiologia Ambiental (LAMAB) do Departamento de Biologia da Universidade Federal do Ceará (UFC).

\section{Caracterização cultural}

$\mathrm{Na}$ caracterização cultural, utilizou-se as estirpes autenticadas, as quais foram repicadas em placas de Petri com o meio de cultura YMA contendo o indicador de $\mathrm{pH}$, o corante azul de bromotimol, conforme Hungria; Araújo (1994). As características verificadas foram: velocidade de crescimento, modificação de $\mathrm{pH}$ do meio, muco e diâmetro das colônias.

Estirpes que exibiram crescimento considerável em até três dias de incubação foram classificadas como de crescimento rápido e as que exibiram crescimento considerável em período maior que três dias de incubação, como de crescimento lento. Em relação à modificação do $\mathrm{pH}$ do meio depois do crescimento, aquelas em 
que o meio de cultura, contendo o indicador de $\mathrm{pH}$, assumiu a cor amarela foram qualificadas como acidificantes e as que o meio assumiu cor azul, alcalinizantes. A leitura de $\mathrm{pH}$ não foi realizada uma vez que, a alteração do $\mathrm{pH}$ do meio é uma característica qualitativa. $\mathrm{O}$ meio foi usado o apenas como indicador de $\mathrm{pH}$, que adquire cor amarela quando fica ácido e cor azul quando alcalino, cor verde quando permanece neutro. Quanto a formação do muco, as estirpes foram categorizadas como viscosa, seca, gomosa e butírica. Sobre o diâmetro das colônias, as mesmas foram identificadas como puntiforme, quando demostraram diâmetro inferior a 0,5 $\mathrm{mm}$, inferior a $1 \mathrm{~mm}$, igual a $1 \mathrm{~mm}$, maior que $1 \mathrm{~mm}$, inferior a $2 \mathrm{~mm}$, e superior a 2 mm (MARTINS et al., 1997).

\section{pH}

A avaliação da tolerância das estirpes a valores extremos de $\mathrm{pH}$ foi realizada em triplicata, usando o meio YM (VINCENT, 1970) modificado, com pH ajustado para 4 adicionando $\mathrm{HCl}$ e $\mathrm{pH} 10$ adicionando $\mathrm{NaOH}$. As estirpes permaneceram sob a agitação a $150 \mathrm{rpm}$ em temperatura ambiente. A avaliação do crescimento foi realizada sete dias após a incubação. Tubos que apresentaram turbidez no caldo, comparado ao controle negativo, foram classificados como resultado positivo para o crescimento da cultura e os que não apresentaram turbidez, como resultado negativo (PINHEIRO et al,2014).

\section{Análise estatística}

Estirpes padrão, foram utilizadas como referência para os testes realizados: BR3471 (Cupriavidus taiwanensis), BR 3486 (Burkholderia phymatum), INPA 03-11B -Bradyrhizobium sp (BR 3301), UFLA 03-84-Bradyrhizobium sp. (BR 3302), BR 3267(Bradyrhizobium sp), BR 3262 (Bradyrhizobium sp), BR 2003 (Bradyrhizobium elkanii).

Os resultados foram transformados em uma matriz binária de dados, onde "0" é crescimento positivo e "1" crescimento negativo. Os dados foram empregados para criar uma matriz de similaridade a fim de elaboração do dendrograma no software Paleontological Statistics Software Package for Education and Data Analysis. (PAST), o que possibilitou o agrupamento das estirpes similares. Adotou-se o algorismo contido no Unweighted Pair Group Methodizing Arithmetic Averages (UPGMA). Os testes fenotípicos analisados nesse experimento geram variáveis qualitativas binárias, determinadas pelo aparecimento ou não de uma certa característica, após as análises laboratoriais. Os micro-organismos que apresentam maior coincidência de existência e/ou inexistência de certas características são julgados mais similares entre si. O coeficiente de Jaccard foi adotado para a determinação de similaridade (CALVACANTE, 2015).

\section{RESULTADOS E DISCUSSÃO}

A partir das amostras de solo obteve-se 24 isolados, destes, 19 conseguiram formar nódulos radiculares, sendo certificados como estirpes de rizóbio, enquanto cinco não nodularam.

Das 19 estirpes, somente uma delas alcalinizou o $\mathrm{pH}$ do meio, nas demais o $\mathrm{pH}$ não foi alterado, permanecendo neutro. Todas as estirpes exibiram crescimento lento, com consistência do muco butírica. No que se refere ao diâmetro médio das colônias, uma (5,26\%) é puntiforme, 15 (quinze) (78,94\%) tem diâmetro inferior a 1 $\mathrm{mm}$ e três delas $(15,78 \%)$ o diâmetro é superior a $1 \mathrm{~mm}$. 
A modificação de $\mathrm{pH}$ em meio de cultura YMA, é frequentemente uma característica para distinção dos gêneros Mesorhizobium, Rhizobium e Sinorhizobium que possuem a propriedade de tornar o meio de cultura ácido, enquanto que Azorhizobium e Bradyrhizobium tornam o meio alcalino (LIMA et al., 2012). Todas as amostras avaliadas são oriundas do Nordeste e segundo Martins et al. (1995) estirpes que não alteram o pH do meio são mais frequentes no sertão nordestino, onde os solos são geralmente neutros ou alcalinos.

Quanto as sete estirpes padrão, quatro $(57,14 \%)$ tornaram o meio da cultura ácido, uma (14,28\%) o meio tornou-se alcalino e duas $(28,57 \%)$ não alteraram o $\mathrm{pH}$ do mesmo. Seis estirpes $(87,71 \%)$ demonstraram crescimento lento e uma $(14,28 \%)$ apresentou crescimento rápido. Quanto ao diâmetro das colônias, duas $(28,57 \%)$ apresentaram diâmetro superior a $1 \mathrm{~mm}$, e cinco $(71,42 \%)$ diâmetro superior a 2 $\mathrm{mm}$. No tocante a consistência do muco, três estirpes $(14,85 \%)$ exibiram colônias com muco viscoso e quatro $(57,14 \%)$ butírico (quadro 1$)$.

Esta alteração de $\mathrm{pH}$ promovida pelo rizóbio no meio YMA pode ser em decorrência do uso preferencial de açúcares, como a galactose, pelos rizóbios de crescimento rápido, acompanhada da excreção de ácidos orgânicos e compostos nitrogenados pelos rizóbios de crescimento lento, resultando na liberação de cátions (COUTINHO et al., 1999) (MARTINS et al., 1997).

No que se refere a tolerância a pH extremos, as estirpes cresceram apenas no $\mathrm{pH}$ alcalino $(\mathrm{pH} 10)$, não tolerando o meio ácido $(\mathrm{pH} 4)$. Em relação as estirpes padrões, das sete testadas, 5 toleraram as duas faixas de $\mathrm{pH}$ avaliados e 2 toleraram somente o pH alcalino. Feitoza et al. (2015) testando estirpes de rizóbios provenientes do semiárido, mostraram que 25 das 28 estirpes testadas manifestaram tolerância ao meio ácido $(\mathrm{pH} 4), 24$ toleraram o meio básico $(\mathrm{pH} \mathrm{10}) \mathrm{e}$ 21 toleraram ambos os valores de $\mathrm{pH}$ avaliados.

QUADRO 1. Características culturais das estirpes de rizóbio do Baixo Acaraú e das estirpes padrão.

\begin{tabular}{|c|c|c|c|c|}
\hline \multirow[b]{2}{*}{ Estipes } & \multicolumn{4}{|c|}{ Características culturais } \\
\hline & $\begin{array}{l}\text { Velocidade de } \\
\text { Crescimento }\end{array}$ & $\begin{array}{c}\text { Alteração pH do } \\
\text { meio }\end{array}$ & $\begin{array}{l}\text { Consistência } \\
\text { muco }\end{array}$ & $\begin{array}{l}\text { Diâmetro colônia } \\
\qquad(\mathrm{mm})\end{array}$ \\
\hline BR 3471 & Lento & Alcalino & Butírica & $>2$ \\
\hline BR 3486 & Rápido & Ácido & Butírica & $>2$ \\
\hline BR 3301 & Lento & Alcalino & Viscosa & $>1$ \\
\hline BR 3262 & Lento & Alcalino & Viscosa & $>2$ \\
\hline BR 2003 & Lento & Neutro & Butírica & $>2$ \\
\hline BR 3302 & Lento & Alcalino & Viscosa & $>1$ \\
\hline BR 3267 & Lento & Neutro & Butírica & $>2$ \\
\hline L112 & Lento & Neutro & Butírica & $>1$ \\
\hline L113 & Lento & Neutro & Butírica & $>1$ \\
\hline L114 & Lento & Neutro & Butírica & $<1$ \\
\hline L115 & Lento & Neutro & Butírica & $<1$ \\
\hline L116 & Lento & Neutro & Butírica & $<1$ \\
\hline L117 & Lento & Neutro & Butírica & $<1$ \\
\hline L118 & Lento & Neutro & Butírica & $<1$ \\
\hline L119 & Lento & Neutro & Butírica & $<1$ \\
\hline L120 & Lento & Neutro & Butírica & $>1$ \\
\hline L121 & Lento & Neutro & Butírica & $<1$ \\
\hline L122 & Lento & Neutro & Butírica & $<1$ \\
\hline L123 & Lento & Neutro & Butírica & $<1$ \\
\hline L124 & Lento & Neutro & Butírica & $<1$ \\
\hline L125 & Lento & Neutro & Butírica & $<1$ \\
\hline ENCICLOF & FERA, Cent & $n$ & $15 \mathrm{n} .2$ & 2018 \\
\hline
\end{tabular}




\begin{tabular}{|c|c|c|c|}
\hline L126 & Lento & Neutro & Butírica \\
\hline L127 & Lento & Alcalino & Butírica \\
\hline 28 & Lento & Neutro & Butírica \\
\hline & Lento & Neutro & Butírica \\
\hline & Lento & Neutro & Butírica \\
\hline
\end{tabular}

Stefan et al. (2018) trabalhando com 60 estirpes isoladas de plantas de trevo na Romênia, mostraram que todas cresceram em pH entre 4,8 e 7,8, contudo metade dos isolados não foram capazes de tolerar $\mathrm{pH}$ de 8,8 . Tais autores relatam que a acidez do solo pode influenciar o crescimento dos rizóbios, além do efeito direto da acidez, pela liberação de compostos tóxicos como metais pesados e outras partículas.

A partir dos dados referentes às características culturais e de tolerância a pH extremos obteve-se um dendrograma de similaridade (Figura 1). Foi verificada a formação de dois grupos principais ao nível de $67 \%$ de similaridade. O grupo I é constituído de três estirpes que exibiram colônias de diâmetro superior a $1 \mathrm{~mm}$. O grupo II é composto por 14 estirpes com colônias de diâmetro inferior a $1 \mathrm{~mm}$. Nenhuma das estirpes padrão compuseram esses grupos no nível de corte apresentado, apenas ao nível de $60 \%$ de similaridade há duas estirpes padrões mais semelhantes, a BR 2003 e BR 3267, que possuem velocidade de crescimento lenta, $\mathrm{pH}$ do meio neutro e ambas as estirpes toleraram o nível de $\mathrm{pH} 10$.

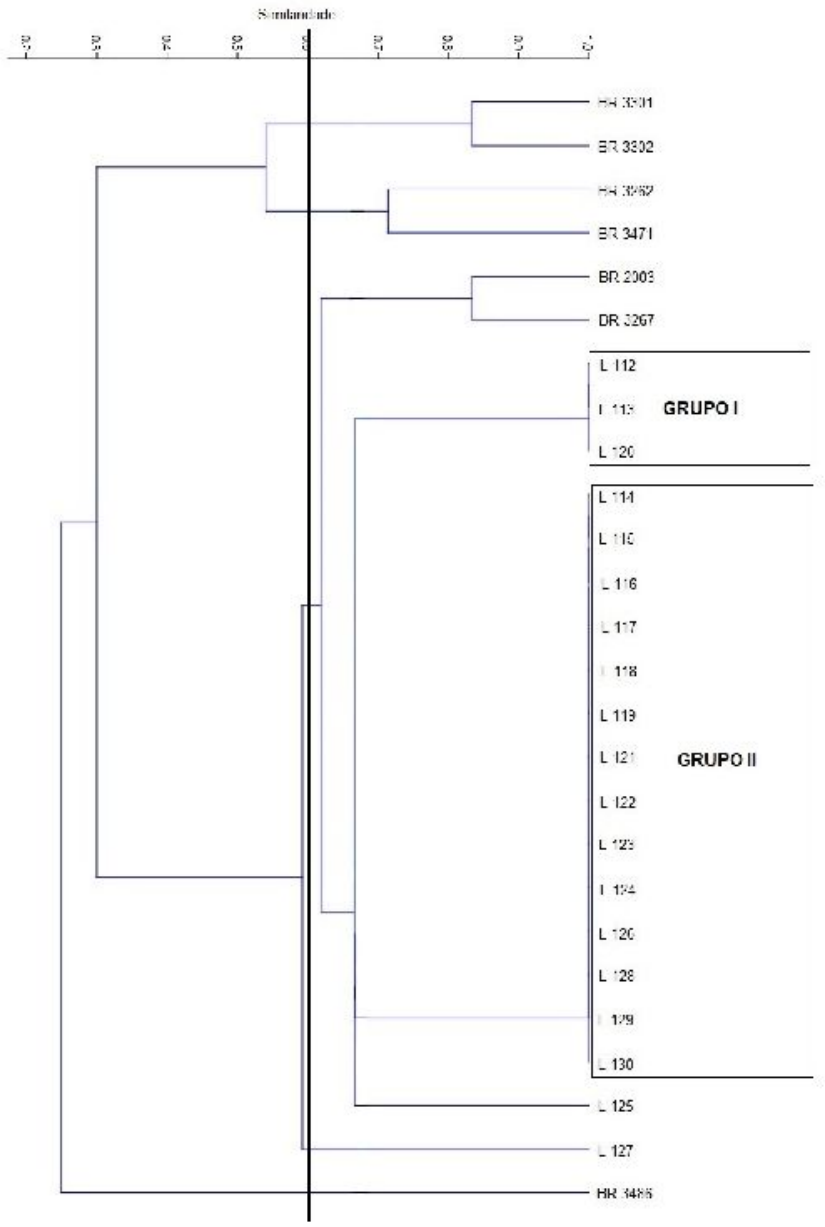

FIGURA 1. Dendrograma das características culturais e de tolerância à pH extremos das 19 estirpes e 7 padrões. A linha vertical aponta grupos com cerca de $60 \%$ de similaridade. 
Nas estirpes testadas não houve variação quanto a velocidade de crescimento e alteração de $\mathrm{pH}$ do meio, diferindo apenas no diâmetro das colônias, gerando assim dois grupos. Rizóbios pertencentes ao gênero Bradyrhizobium spp, geralmente apresentam velocidade de crescimento lento e são capazes de alcalinizar o meio de cultura. Os que alcalinizam o meio representam uma forma menos evoluída do que aqueles que acidificam. De modo geral, os rizóbios que alcalinizam o meio e apresentam crescimento lento, parecem ter co-evoluído com leguminosas de origem tropical. Solos tropicais são mais ácidos e é possível que a habilidade de alcalinizar o meio represente uma vantagem seletiva (MARTINS et al., 1997). Os resultados desse estudo indicam que as estirpes da região do Baixo Acaraú pertencem ao mesmo gênero devido as semelhanças de suas características, sendo necessários estudos complementares.

\section{CONCLUSÃO}

Os rizóbios não mostraram significativas variações nas características culturais e apresentaram tolerância somente ao pH alcalino.

\section{REFERÊNCIAS}

APPUNU, C.; DHAR, B. Symbiotic effectiveness of acid tolerant Bradyrhizobium strains with soybean in low pH soil. African Journal of Biotechnology v. 5, p. 842845, 2006.

ARAÚJO, C. L.; GUALTER, R. M. R. Caracterização morfoisiológica de bactérias nativas de solos do Cerrado isoladas de nódulos de feijão-caupi. Biotemas, v. 30, n. 1, p. 25-35, 2017. Disponível em: <https://doi.org/10.5007/21757925.2017v30n1p25> DOI: 10.5007/2175-7925.2017v30n1p25

BREDEMEIER, C.; MUNDSTOCK, C. M. Regulação da absorção e assimilação do nitrogênio nas plantas. Ciência Rural, v. 30, n. 2, p. 365-372, 2000. Disponível em: <http://dx.doi.org/10.1590/S0103-84782000000200029 >. DOI: 10.1590/S010384782000000200029

CARDOSO, E. J. B. N.; ANDREOTE, F. D. Microbiologia do solo [recurso eletrônico], Piracicaba: ESALQ, p. 221, 2016. Disponível em: <http://www.livrosabertos.sibi.usp.br/portaldelivrosUSP/catalog/view/109/92/461-1> DOI: $10.11606 / 9788586481567$

CAVALCANTE, F. G.; SOUSA, J. B. S.; BERTINI, C. H. C. M.; MARTINS S. C. S.; MARTINS, C. M. Tolerância à salinidade e uso de fontes de carbono de estirpes de rizóbio oriundas de Pentecoste-CE. Enciclopédia Biosfera, Centro Científico Conhecer, v.11, n. 21; p. 2987-2397, 2015.

COUTINHO, H. L. C.; OLIVEIRA, V. M.; LOVATO, A.; MAIA, A. H. N.; MANFIO, G. P. Evaluation of the diversity of rhizobia in Brazilian agricultural soils cultivated with soybeans. Applied Soil Ecology. v. 13, n. 2, p. 159-167, 1999. Disponível em: <https://doi.org/10.1016/S0929-1393(99)00031-1> DOI: 10.1016/S0929-1393(99)000 $31-1$ 
EHRHARDT-BROCARDO, N. C. M.; STOCCO, P.; TRAMONTIN, A. L.; FILHO. L. C. I. O; SANTOS, J. C. P. Diversidade cultural, morfológica e genética de diazotróficos isolados de nódulos de Bracatinga. Revista Árvore, v. 39, n. 5, p. 923-933, 2015. Disponível em: <http://dx.doi.org/10.1590/0100-67622015000500015>. DOl: $10.1590 / 0100-67622015000500015$

FEITOZA, R. M.; SILVA, L. L.; PINHEIRO, M. S.; MARTINS, S. C. S., MARTINS, C. M. Diversidade fisiológica e bioquímica de estirpes de rizóbio do Semiárido. Enciclopédia Biosfera, Centro Científico Conhecer. v. 11, n. 21, p. 794-806, 2015.

HAMMER, O.; HARPER, D. A. T.; RYAN, P. D. PAST: Paleontological statistics. software package for education and data analysis. Palaeontologia Electronica. $v$. 4, n. 1, p. 9, 2001. Disponível em: <http://palaeoelectronica.org/2001_1/past/issue1_ 01.htm>

HUNGRIA, M.; MENNA, P.; DELAMUTA, J. R. M. Bradyrhizobium, the ancestor of all rhizobia: phylogeny of housekeeping and nitrogenfixation genes. In: Biological Nitrogen Fixation. Wiley-Blackwell, 2015. p. 191-202. Disponível em: < https://doi.org/10.1002/9781119053095.ch18 >. DOI:10.1002/9781119053095.ch18

HUNGRIA, M.; ARAUJO, R. S. Coleta de nódulos e isolamento de rizóbios. Manual de métodos empregados em estudos de microbiologia agrícola. EMBRAPA-SPI, 1994. Disponível em: < http://ainfo.cnptia.embrapa.br/digital/bitstream/CNPAF/8927/ 1/doc 46.pdf>

LIMA, A. A.; FERNANDES JÚNIOR, P. I.; PASSOS, S. R.; PAULO, F. S; NOSOLINE, S. M.; FARIA, S. M.; GUERRA, J. G. M.; RUMJANEK, N. G.; XAVIER, G. R. Diversidade e capacidade simbiótica de rizóbios isolados de nódulos de Mucuna-Cinza e Mucuna-Anã. Revista Brasileira de Ciência do Solo, v. 36, n. 2, p. 337-348 2012. Disponível em: < https://dx.doi.org/10.1590/S010006832012000200003 > DOI: 10.1590/S0100-06832012000200003

MARIN, V. A.; BALDANI, V. L. D.; TEIXEIRA, K. R. S.; BALDANI, J. I. Fixação biológica de nitrogênio: bactérias fixadoras de nitrogênio de importância para a agricultura tropical. EMBRAPA-CNPAB. Documentos, 91, 1999. Disponível em: < https://www.infoteca.cnptia.embrapa.br/infoteca/bitstream/doc/598661/1/doc 091 .pdf $>$

MARTINS, L. M. V.; XAVIER, G. R.; NEVES, M. C. P.; RUMJANEK, N. G. Características relativas ao crescimento em meio de cultura e a morfologia de colônias de "rizóbio". (EMBRAPA-CNPAB. Comunicado Técnico, 19).1997.

MARTINS, L. M. V.; RUMJANEK, N. G.; NEVES, M. C. P. Diversity of cowpea nodulating rhizobia isolated from the semi-arid Northeast region of Brazil. Anais da Academia Brasileira de Ciências. v. 67, p. 467-471, 1995.

NAVROSKI, D.; SILVA, T. L.; SCHERER, A. J.; APPEL, R. J. C.; FAVETTA, A.; BARREIROS, M. A. B.; GRANGE, L. Diversidade morfológica de rizobactérias obtidas de solos sob distintos manejos de cultivo da região oeste do Paraná. Revista Brasileira de Energias Renováveis, v. 4, p. 117- 128, 2015. Disponível em: <http://dx.doi.org/10.5380/rber.v4i2.42838> DOI: 10.5380/rber.v4i2.42838 
PINHEIRO, M. S; SOUSA, J. B.; BERTINI, C. H. C. M.; MARTINS, S. C. S.; MARTINS, C. M. Isolamento e seleção de estirpes de rizóbios nativas do semiárido tolerantes a estresses ambientais. Enciclopédia Biosfera, v.10, n.18; p. 2071-2082, 2014

PEREIRA, D. S.; NÓBREGA, R. D. A.; LUSTOSA FILHO, J. F.; DIAS, A.S.; VELOSO, G. S.; SOUZA, E. A. Crescimento e nodulação natural de feijão-caupi em solos e mineração de chumbo adubados com resíduo de sisal. Revista Brasileira de Agropecuária Sustentável (RBAS), v. 7, n. 4, p. 34-42, 2017. Disponível em: <https://doi.org/10.21206/bjsa.v7i4.426> DOI: 10.21206/bjsa.v7i4.426

RODRIGUES, D. R., SILVA, A. F. D., CAVALCANTI, M. I. P., ESCOBAR, I. E. C., FRAIZ, A. C. R., RIBEIRO, P. R. D. A., FERREIRA NETO, R. A., FREITAS, A. D. S.D., FERNANDES-JÚNIOR, P. I. Phenotypic, genetic and symbiotic characterization of Erythrina velutina rhizobia from Caatinga dry forest. Brazilian Journal of Microbiology, v 49, n. 3, p 503-512, 2018. Disponível em: < https://doi.org/10.1016/j.bjm.2017.09.007 >. DOI: 10.1016/j.bjm.2017.09.007

SILVA, L. L.; PINHEIRO, M. S.; SOUSA, J. B.; MARTINS, S. C. S; MARTINS C. M. Diversidade de rizóbio da Unidade de Conservação Parque Nacional de Ubajara No Estado do Ceará. Enciclopédia Biosfera, v. 10, n. 19; p. 2141-2156, 2014.

SOUSA, J. B.; PINHEIRO, M. S.; SILVA, L. L; MARTINS, S. C. S; MARTINS C. M. Caracterização de bactérias nativas de solo do semiárido isoladas de nódulos de feijão-caupi. Enciclopédia Biosfera, v. 10, n. 19; p. 2797-2806, 2014.

STEFAN, A.; VAN CAUWENBERGHE, J.; ROSU, C. M., STEDEL, C., LABROU, N. E., FLEMETAKIS, E.; EFROSE, R. C. Genetic diversity and structure of Rhizobium leguminosarum populations associated with clover plants are influenced by local environmental variables. Systematic and Applied Microbiology. v. 41, n. 3, p. 251259, 2018. Disponível em:< https://doi.org/10.1016/j.syapm.2018.01.007> DOI: 10.1016/j.syapm.2018.01.007

VINCENT, J. M. Manual for the practical study of root nodule bacteria. Oxford: Blackwell Scientific Publications, p.164,1970. 